\title{
Quantitative Analysis of the Relationship between Three Psychological Parameters Based on Swallowtail Catastrophe Model
}

\author{
Asti Meiza, ${ }^{1}$ Sutawanir Darwis, ${ }^{2}$ Agus Yodi Gunawan, ${ }^{3}$ and Efi Fitriana ${ }^{4}$ \\ ${ }^{1}$ Psychology Faculty, UIN Sunan Gunung Djati-Bandung, Bandung, Indonesia \\ ${ }^{2}$ Statistical Research Division of Mathematics and Natural Faculty, Bandung Institute of Technology, Bandung, Indonesia \\ ${ }^{3}$ Industrial and Finance Research Division of Mathematics and Natural Faculty, Bandung Institute of Technology, Bandung, Indonesia \\ ${ }^{4}$ Faculty of Psychology, Padjadjaran University, Bandung, Indonesia
}

Correspondence should be addressed to Asti Meiza; asti.meiza@uinsgd.ac.id

Received 8 June 2017; Revised 26 July 2017; Accepted 9 August 2017; Published 26 September 2017

Academic Editor: Niansheng Tang

Copyright (C) 2017 Asti Meiza et al. This is an open access article distributed under the Creative Commons Attribution License, which permits unrestricted use, distribution, and reproduction in any medium, provided the original work is properly cited.

\begin{abstract}
A sudden jump in the value of the state variable in a certain dynamical system can be studied through a catastrophe model. This paper presents an application of catastrophe model to solve psychological problems. Since we will have three psychological aspects or parameters, intelligence (I), emotion (E), and adversity (A), a Swallowtail catastrophe model is considered to be an appropriate one. Our methodology consists of three steps: solving the Swallowtail potential function, finding the critical points up to and including threefold degenerates, and fitting the model into our measured data. Using a polynomial curve fitting derived from the potential function of Swallowtail catastrophe model, relations among three parameters combinations are analyzed. Results show that there are catastrophe phenomena for each relation, meaning that a small change in one psychological aspect may cause a dramatic change in another aspect.
\end{abstract}

\section{Introduction}

A catastrophe phenomenon arising from psychological problems has first been discussed by Arnold [1]. In that paper, he characterized a creative personality of a scientist, as well as a maniac, by the following three parameters: technical proficiency, enthusiasm, and achievement. He found that scientist and maniac have differences in their performance dramatically. In fact, the achievement of scientist mainly depended on his technical proficiency and enthusiasm. If enthusiasm was not great, the achievement grew monotonically and fairly slow with technical proficiency. If enthusiasm was sufficiently great then qualitatively dramatic phenomena start to occur due to a small variation in technical proficiency, while for maniac, he concluded that the latter phenomenon would not occur. A maniac having similar enthusiasm with scientist could not change his achievement because their technical proficiencies were different. This phenomenon was well modelled by him as Cusp catastrophe model.
Other catastrophe models related to psychological problems were also studied by [2-6] (Brezeale, 2011). However, their model was limited to Cusp model. To name a few, Van der Maas et al. have constructed a deterministic Cusp catastrophe for "political attitude" as a state variable and "information" and "involvement" as the two control parameters. Cusp was fitted using $\mathrm{R}$ routine in the common use and also used to fit a sudden transition data [7]. Cusp catastrophe model was also used by [5] to model the intelligent phenomenon of students (their intelligences and emotions) when students from various departments were grouped into one class. Other fitting models based on an application of estimation theory were worked out by Cobb [4]. To some extent, catastrophe model was extended to include more than two control parameters. For instance, [8] studied relations among three parameters of traffic flow: velocity, density, and flow, by using a Swallowtail catastrophe model. The butterfly catastrophe model for describing and predicting performance changes in an educational setting 
was studied by [9] that included controlled parameters of students such as subject's abilities, intrinsic, and extrinsic motivational factors and organizational climate variables. $\mathrm{Wu}$ et al., 2014, discussed a butterfly catastrophe model for wheat aphid population dynamics. Until now to our knowledge, catastrophe model for three control parameters, especially for physiological problems, is still limited.

In addition, next, we describe more relation between intelligence and emotion. There are some ways to define intelligence. Intelligence covers creativity, personality, character, knowledge, or wisdom, although not all psychologists agree with these. Usually, intelligence refers to ability or mental capacity in thinking [10]. Generally, there are some kinds of intelligence, that is, Intelligence Quotient (IQ), Emotional Quotient (EQ), and Spiritual Quotient (SQ), although the last kind is still debatable in expert besides the previous intelligences, also known Multiple Intelligence (MI) that is proposed by Howard Gardner. In particular, we will see the relation and differences between IQ and EQ. Most people know Intelligence Quotient (IQ). IQ is used to determine academic abilities, understand and apply information to skills, logical reasoning, word comprehension, math skills, abstract, and spatial thinking, and filter irrelevant information. French psychologist Alfred Binet was one of the key developers of IQ test, what later became known as the Stanford-Binet test, while EQ is defined as an individual's ability to identify, evaluate, control, and express emotions. Daniel Goleman is the one who proposed EQ. As believed for a long time, IQ was the ultimate measure for success in careers and life in general, but there were some studies that show a direct relation between higher EQ and successful. From a brain study in Vietnam, a significant overlap between general intelligence (IQ) and Emotional Intelligence was found, in both behavioral measures and brain activity. Higher scores on intelligence tests have a better personality and predicted higher performance on measures of Emotional Intelligence. Also many of the same brain regions that are used for the two types of intelligence were found [11].

In this paper, we extend the work of Meiza [5] by adding one extra control parameter, namely, adversity, and then apply the Swallowtail catastrophe to model the intelligent phenomena. We include adversity since it is believed that this aspect will also contribute to one's intelligence ability. It is a person's ability to be able to withstand the difficulties and able to turn challenges into opportunities [12]. The line of our method will follow the idea of [8]. We will apply our method to our measured data. Regression concepts to fit the data to the Swallowtail model are then used.

This paper is organized as follows. In Section 2, we propose the methodology. We solved the Swallowtail potential function and fond the critical points up to and including threefold degenerates. We fit the model by our measured data. In Section 3, we present Results and Conclusion.

\section{Methodology}

2.1. Instruments. In this research we refer to empirical data of psycho test resulting from the research subjects which are the employees from a company. The data were obtained from three instruments, that is, IST, Pauli, and EPPS. In the following a brief explanation of the three psychological measuring instruments is described.

(i) The IST Test (Intelligence Structure Test) is one of the psychological tests to measure verbal, numerical, and figural level of one's intelligence developed by Rudolf Amthauer in Germany in 1953. This test consists of 9 subtests, that is, SE (complete the sentence); WA (find a different word); AN (find the related words); GE (find synonym of words); RA (simple count); ZR (number series); FA (construct the shapes); WU (cube); and ME (remember the words) [13].

(ii) The Pauli Test is an improvement and refinement of the Kraepelin test compiled by Emil Kraepelin, a late 19th century psychiatrist who used a tool to diagnose brain disorders of Alzheimer's and dementia. This test is perfected in such a way by Professor Pauli making it possible to get data about personality [14].

(iii) The EPPS (Edwards Personal Preference Schedule) Test was developed by psychologist and University of Washington Professor Allen L. Edwards. The EPPS Test is a forced choice, objective, and nonprojective personality inventory. Edwards derived the test content from the human needs system theory proposed by Murray which measures the rating of individuals in fifteen normal needs or motives [15].

The empirical data consisted of these three instruments which are combination of three aspects, that is, intelligence, emotion, and adversity.

2.2. The Swallowtail Catastrophe Model. In this part we start with introducing the Swallowtail catastrophe model that we will use. Next, we derive the catastrophe control parameters as function of parameters of our measured data. Analyzing the degenerate critical points of catastrophe potential function is proposed to determine the qualitative properties of potential function at those points. The potential function of Swallowtail catastrophe model is defined by [16]

$$
F(x)=x^{5}+\alpha x^{3}+\beta x^{2}+\gamma x,
$$

where $\alpha, \beta$, and $\gamma$ are control parameters and $x$ is the state variable. Equilibrium points are obtained by taking the first derivative of (1) with respect to $x$ equal to 0 ; this is given by

$$
5 x^{4}+3 \alpha x^{2}+2 \beta x+\gamma=0 .
$$

Singular points which are a subset of the equilibrium surface of (2) are obtained by vanishing the second derivative of (1) with respect to $x$

$$
20 x^{3}+6 \alpha x+2 \beta=0 \text {. }
$$

In the sequel, we shall formulate control parameters $\alpha, \beta$, and $\gamma$, as function of the state variable. To this end, we shall proceed as follows. 


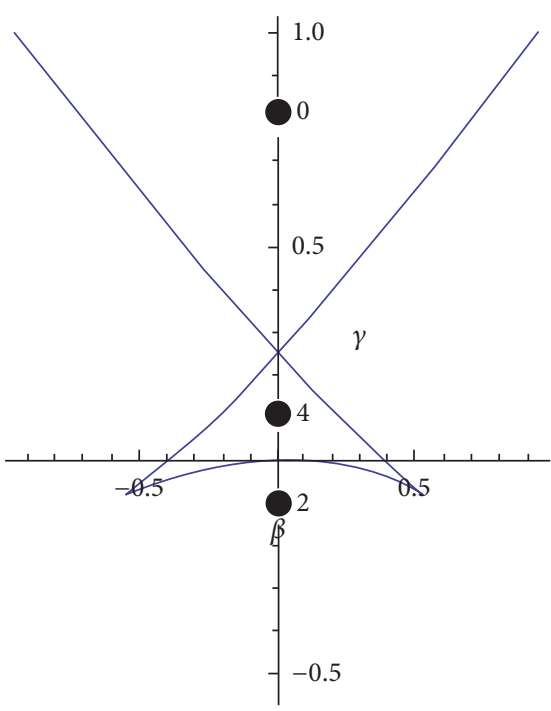

(a)

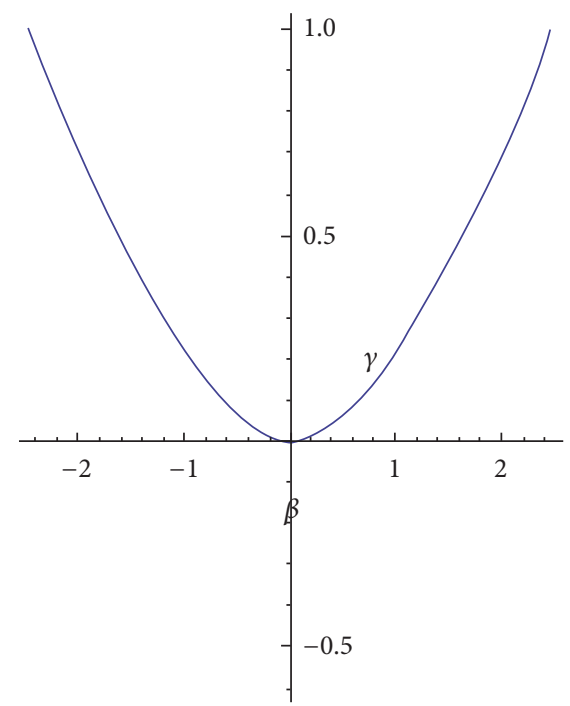

(b)

Figure 1: The set of Swallowtail ramification points for $\alpha<0$ (a) and $\alpha>0$ (b).

Next, we shall state $\beta$ and $\gamma$ as function of $x$ and $\alpha$. From (3), we obtain

$$
\beta=-10 x^{3}-3 \alpha x \text {. }
$$

Substituting (4) into (2) we find

$$
\gamma=15 x^{4}+3 \alpha x^{2} .
$$

The derivation of $\gamma$ and $\beta$ with respect to $x$ is shown by the following equations:

$$
\begin{aligned}
& \frac{d \beta}{d x}=-30 x^{2}-3 \alpha, \\
& \frac{d \gamma}{d x}=60 x^{3}+6 \alpha x .
\end{aligned}
$$

From these two equations we find

$$
\frac{d \gamma}{d x}=-2 x \frac{d \beta}{d x} .
$$

From (4) and (5) we will analyze the relation between $\gamma$ and $\beta$ for fixed $\alpha$. We separate two conditions, $\alpha<0$ and $\alpha>0$, and we plot $\gamma$ as function of $\beta$ as shown in Figure 1 . For $\alpha<0$ and $\beta=0$, we analyze the condition along vertical axis $\gamma$. For the present case, the solution of (2) is given by

$$
x^{2}=\frac{1}{10}\left[-3 \alpha \pm \sqrt{\left(9 \alpha^{2}-20 \gamma\right)}\right] \text {. }
$$

From (8) we observe three conditions as follows:

(1) $\gamma>9 \alpha^{2} / 20$, the equilibrium equation (2) does not have real roots, and $F$ in (1) does not have a critical point [16].

(2) $0<\gamma<9 \alpha^{2} / 20$ and the term $\sqrt{\left(9 \alpha^{2}-20 \gamma\right)}$ is a real number and has value less than $(-3 \alpha)$. For this, there are 4 critical points for $F$ with 2 points of maximum and 2 points of minimum.
(3) $\gamma<0$, two of the solutions of (8) are real numbers, and one of them is negative. This $F$ has only two critical points with one maximum point and one minimum point.

Note that catastrophic phenomena will appear for conditions (2) and (3). We can conclude that these conditions as seen in Figure 1(a). Such points 0 , 2, and 4 show conditions (1) to (3) in sequence above [16].

Next, we apply the theory to the data. We fit our model by using the empirical data: Intelligence score, emotion score, and adversity score from 36 employees of a stateowned company. Considering (2), which describes a balanced curved surface, we use the following polynomial regression, as a statistical procedure of data analysis:

$$
y(x)=x^{4}+p x^{3}+q x^{2}+r x+s .
$$

To synchronize (9) with (2), we use a transformation $z=x+$ $p / 4$. Substitute this form into (9) we obtain

$$
\begin{aligned}
y(z)= & z^{4}+\left(q-\frac{3}{8} p^{2}\right) z^{2}+\left(\frac{p^{3}}{8}-\frac{p q}{2}+r\right) z \\
& +\left(-\frac{3 p^{4}}{256}+\frac{p^{2} q}{16}-\frac{p r}{4}+s\right) .
\end{aligned}
$$

The form of (10) is similar to the balance curved surface of Swallowtail catastrophe model in (2). Considering (2) and (10), we obtain that

$$
\begin{aligned}
& \alpha=\frac{5}{3}\left(q-\frac{3}{8} p^{2}\right), \\
& \beta=\frac{5}{2}\left(\frac{p^{3}}{8}-\frac{p q}{2}+r\right),
\end{aligned}
$$




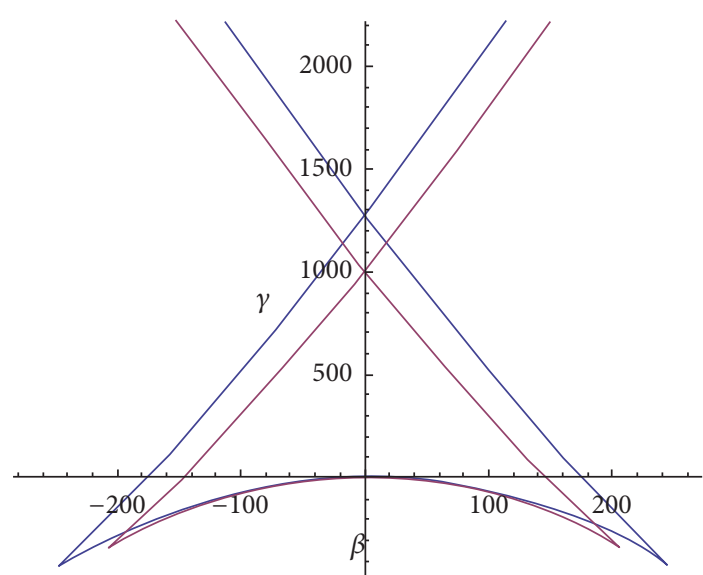

IE

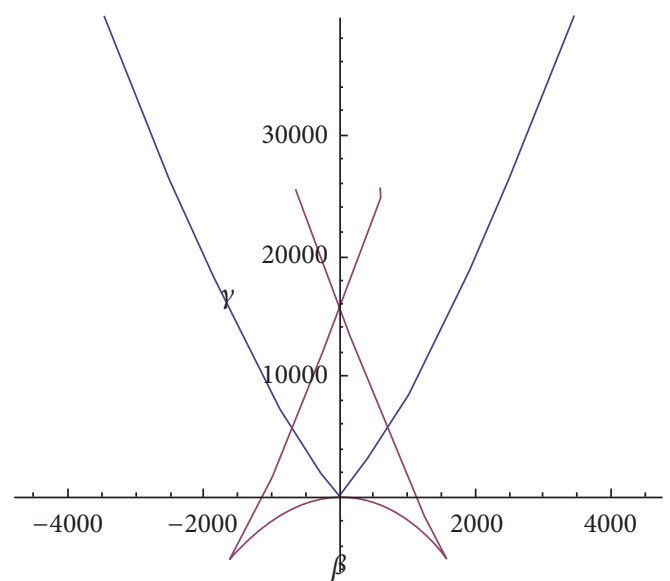

- EA

(a)

(b)

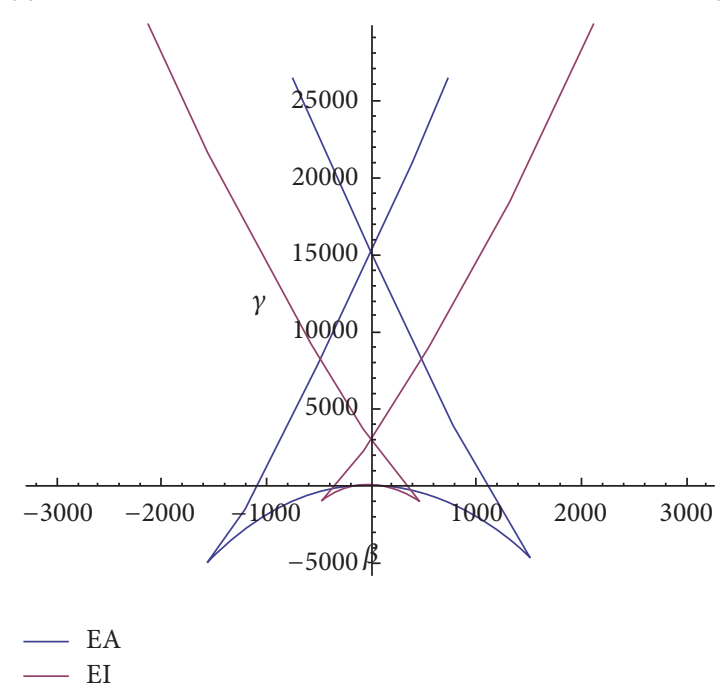

(c)

FIgure 2: The Swallowtail plots for IE-IA case (a), AI-AE case (b), and EA-EI case (c).

$$
\gamma=5\left(-\frac{3 p^{4}}{256}+\frac{p^{2} q}{16}-\frac{p r}{4}+s\right) .
$$

\section{Results and Conclusion}

As the optimization method, we use Fuzzy Linear Programming (FLP). We apply this method to the data with aid of LINGO procedure. On the other step, we also use Maximum Likelihood Estimator to find the best parameter for polynomial regression model. This study is based on our data presented in Figure 3. Note that our data, in general, does not show a function property. In the data, one value in horizontal axis may correspond to many values in the vertical axis. Since we shall apply the polynomial regression as a statistical procedure for data analyze, we should have interval or scale data. For that, we take an average for the data having many values. The averaging results are shown in Figures 4(a)-4(f). As an illustration of our method, let us consider the data of $\mathrm{E}$ with respect to I as seen in Figure 4(a). In the sequel, we shall note this as I-E case where I acts as $x$ and $\mathrm{E}$ as $y$. Applying (9) to fit the averaging data and then using (11), we find three parameters $\alpha, \beta$, and $\gamma$ as seen in the first row of Table 1 . The same line follows for the other cases. All results are presented in Table 1.

From Table 1, we see that all cases have $\alpha<0$. Hence, we will meet with the case described by Figure 1(a). Using the values of three parameters in Table 1, we plot $\gamma$ as a function of $\beta$ given by (4) and (5). Results of all cases are shown in Figures 2(a)-2(c). As shown in Table 1 in which $\beta>0$, our data show catastrophe phenomena.

In a parameterized dynamical system, bifurcation occurs when a change in parameter causes an equilibrium to split into two. While catastrophe occurs, the stability of an equilibrium breaks down causing the system to jump 


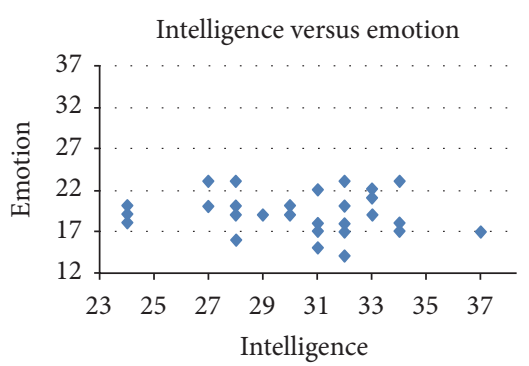

(a)

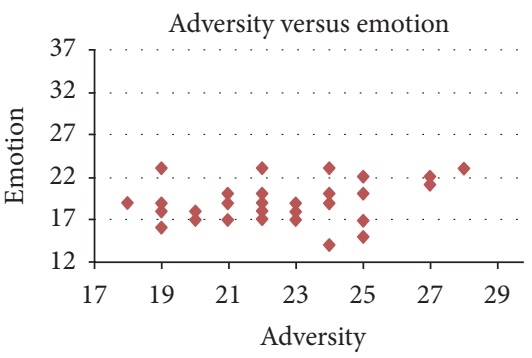

(d)

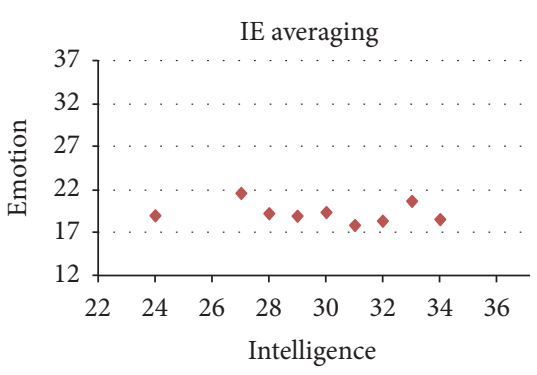

(a)

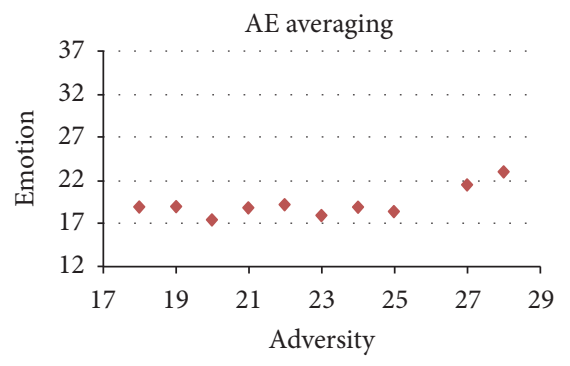

(d)

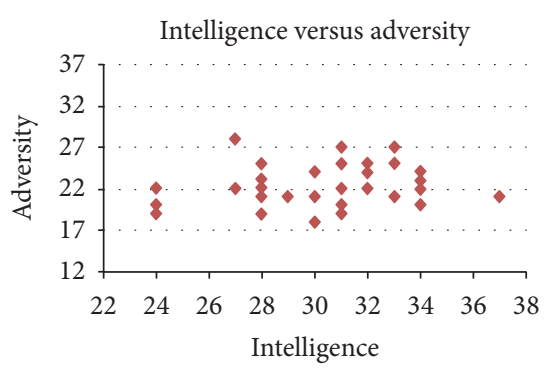

(b)

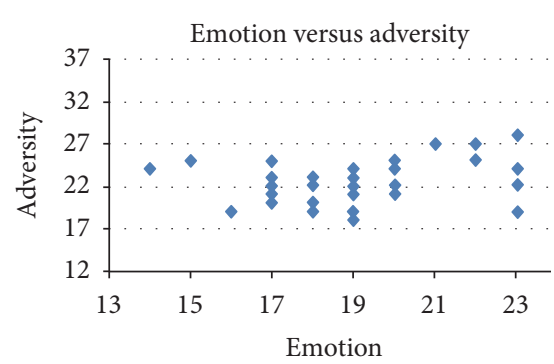

(e)

Figure 3: Scatter plot of raw data.

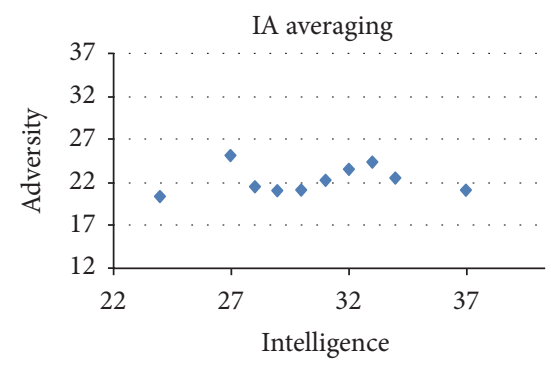

(b)

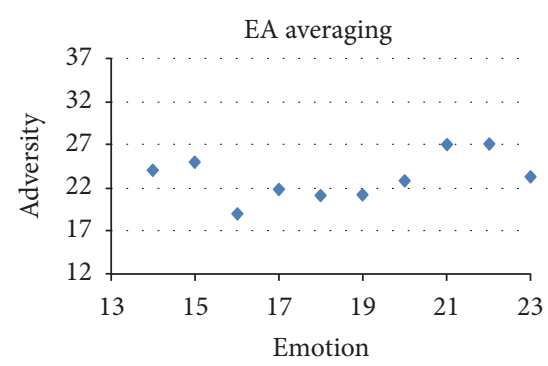

(e)

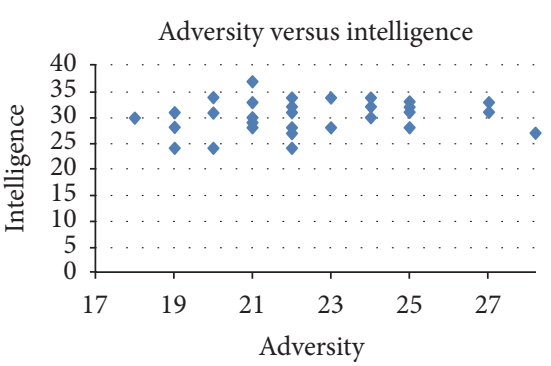

(c)

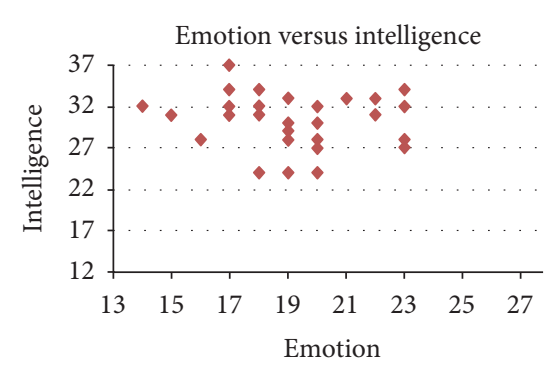

(f)

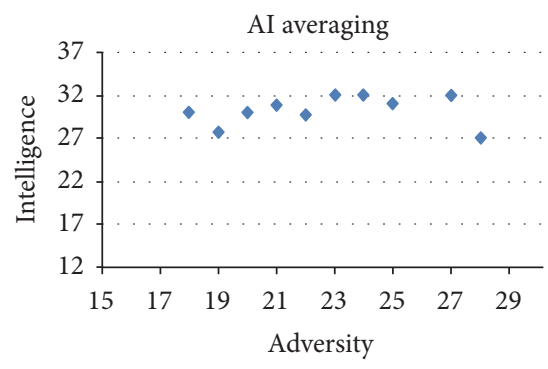

(c)

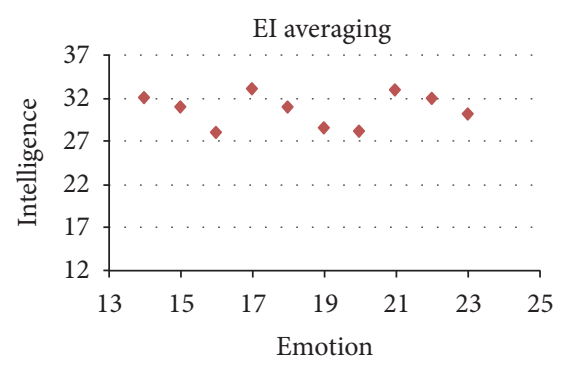

(f)

FIGURE 4: Averaging results from raw data.

into another state [17]. So, by definition, specific variables can act as bifurcation factors because it will distinguish the subject into two different classifications altogether after a jump occurs. As an illustration, in a presidential election, a fanatic supporter of presidential candidate, namely, A, as over time with additional information about the presidential candidate he supports, the supporter may suddenly jump in favor of the presidential candidate B who is the opposite of presidential candidate A. In this research, the specific factor is reviewed with various conditions with specific factors alternately between I, E, and A. For example, if adversity has the specific factor, then two people have the same level of intelligence, but as time goes by, the changes in their emotions can lead to an adversity leap (jump) where they can have a totally different or opposite adversity. In psychological view, we may interpret as follows. Two people who are equally intelligent but have different emotion, can have different performances altogether when facing problems. In this case both will be on different adversity. The first man may have collapsed over time, but the second man can instead turn 
TABLE 1: Results of curve fitting the data by Swallowtail model.

\begin{tabular}{lccc}
\hline Results & $\alpha$ & $\beta$ & $\gamma$ \\
\hline IE & -47.3917 & 959.3617 & $-2.1481 e+004$ \\
IA & -53.400 & 1195.1 & $-2.7221 e+004$ \\
\hline AI & -22.6 & 27.767 & $-5.8235 e+003$ \\
AE & -186.733 & 338.4092 & $-4.7012 e+005$ \\
\hline EI & -182.5563 & 2240.5 & $-3.0158 e+005$ \\
EA & -82.0250 & 1099.7 & $-1.3915 e+004$ \\
\hline
\end{tabular}

the obstacle into an opportunity or perceive the obstacle as a challenge he has to pass.

In psychological view, we may interpret as follows. For EI and EA cases (Figure 2(c)), we choose $\gamma$ in the certain value, that is, 5000 (see Figure 2(c)). With reference to Figure 1(a), we say that $\gamma$ is in condition (2). If we move this value along $\gamma$-axis $(\beta=0)$ until 10,000 , then EA is still in catastrophic phenomenon, but EI is not. We can say that small change in EI would not change dramatically for intelligence, but not for adversity. Adversity will likely change even by small variation in emotion.

As the same line, we can conclude the other cases as follows. In Figure 2(a), for IE and IA cases, the small change of intelligence will lead to a dramatic change for emotion, but not for adversity. Just like AI and AE cases in Figure 2(b), the small change of adversity will lead to a dramatic change for emotion, but not for intelligence.

In general, it can be concluded from the application of Swallowtail catastrophe model to the data that the interaction between intelligence, emotion, and adversity of which emotion and adversity are considered as the control variable, while intelligence is considered as the response (state) variable, will make the relationship not as strong as that in the case of emotion paired with adversity or otherwise. So, if some emotions improved only slightly, the adversity will dramatically increase and vice versa. Meanwhile, if emotion and adversity each pair with intelligence, the slight changes in both of these aspects will not increase dramatic intelligence.

The new present paper offers to the literature the benefits offered by the results of this study; that is, if it can be known which factors are the most significant on the performance, then these factors can be improved.

\section{Appendix}

The raw data in Figures 3(a)-3(f) are the distributions of intelligence, emotion, and adversity scores. We get the scatter plots of each pair, intelligence versus emotion scores, intelligence versus adversity scores, adversity versus intelligence scores, adversity versus emotion scores, emotion versus intelligence scores, and emotion versus adversity scores. In Figures 4(a)-4(f), we get the averaging results from raw data.

\section{References}

[1] V. I. Arnold, Catastrophe Theory, Springer, Berlin, Germany, 1992.

[2] G. R. VandenBos and B. K. Bryant, Eds., Cataclysms, Crises, and Catastrophes: Psychology in Action, Master Lectures Series, 1987.

[3] B. R. Flay, "Catastrophe theory in social psychology: Some applications to attitudes and social behavior," Behavioral Science, vol. 23, no. 4, pp. 335-350, 1978.

[4] L. Cobb, "Estimation Theory for The Cusp Catastrophe Model. Revised Edition," in Proceedings of the American Statistical Association Section on Survey Research Methods, pp. 772-776, 2010.

[5] A. Meiza, A Cusp Catastrophe Model for Intelligence [M.S. thesis], ITB, Bandung, Indonesia, 2006.

[6] D. W. Scott, "Catastrophe theory applications in clinical psychology: A review," Current Psychology, vol. 4, no. 1, pp. 69-86, 1985.

[7] H. L. J. Van der Maas, R. Kolstein, and J. Van der Pligt, "Sudden Transitions in Attitudes," Sociological Methods and Research, vol. 32, no. 2, pp. 125-152, 2003.

[8] J. Guo and D. Wu, "Researching the relationship among traffic flow three parameters based on swallowtail catastrophe model," in Proceedings of the 7th World Congress on Intelligent Control and Automation, WCICA'08, pp. 7181-7186, Chongqing, China, June 2008.

[9] S. J. Guastello, "A Butterfly Catastrophe Model of Motivation in Organizations: Academic Performance," Journal of Applied Psychology, vol. 72, no. 1, pp. 165-182, 1987.

[10] Encarta Reference Library premium, Redmond, Wash, USA, Microsoft Encarta, 2005.

[11] A. K. Barbey, R. Colom, and J. Grafman, "Distributed neural system for emotional intelligence revealed by lesion mapping," Social Cognitive and Affective Neuroscience, vol. 9, no. 3, pp. 265272, 2014.

[12] P. Stolz, Adversity Quotient: Turning Obstacles Become Opportunities, Grasindo, Jakarta, Indonesia, 2000.

[13] L. F. Polhaupessy, Intelligenz Struktur Test (IST) dari Rudolf Amthauer. Suatu Pengantar, Lecture notes in Department of Psychology UNPAD, 1993.

[14] E. N. Sumintardja, Pengantar Psikodiagnostik, Departemen Pendidikan dan Kebudayaan, Faculty of Psychology, UNPAD, Bandung, Indonesia, 2nd edition, 1991.

[15] R. M. Kaplan and D. P. Saccuzzo, Psychological Testing: Principles, Application, and Issues, Wadsworth, Belmont, Calif, USA, 7th edition, 2009.

[16] R. Gilmore, Catastrophe Theory for Scientists and Engineers, John Wiley \& Sons, New York, NY, USA, 1981.

[17] E. C. Zeeman, "Bifurcation, catastrophe, and turbulence," in New Directions in Applied Mathematics (Cleveland, Ohio, 1980), pp. 109-153, 1982.

\section{Conflicts of Interest}

The authors declare that they have no conflicts of interest. 


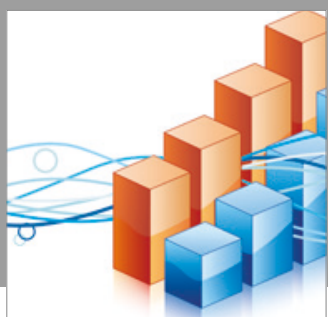

Advances in

Operations Research

vatersals

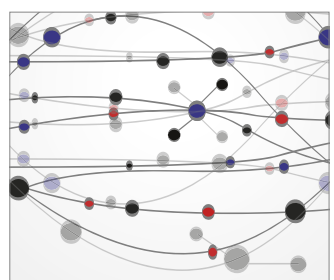

\section{The Scientific} World Journal
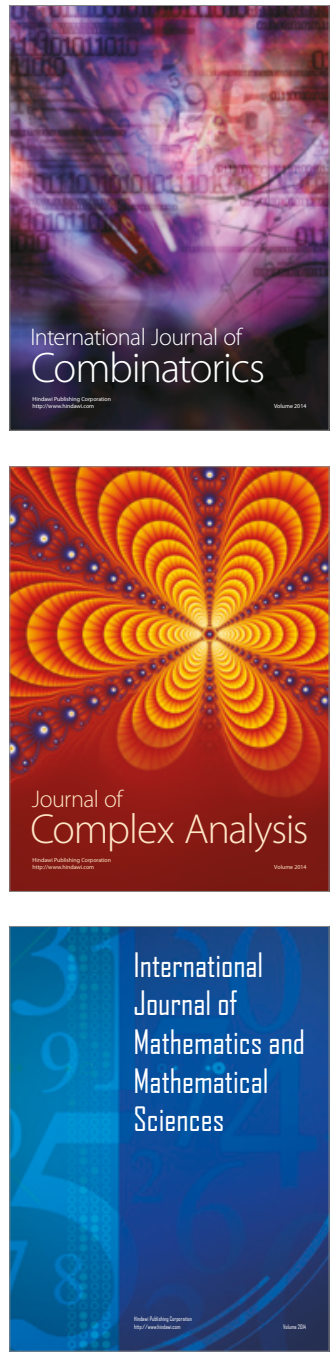
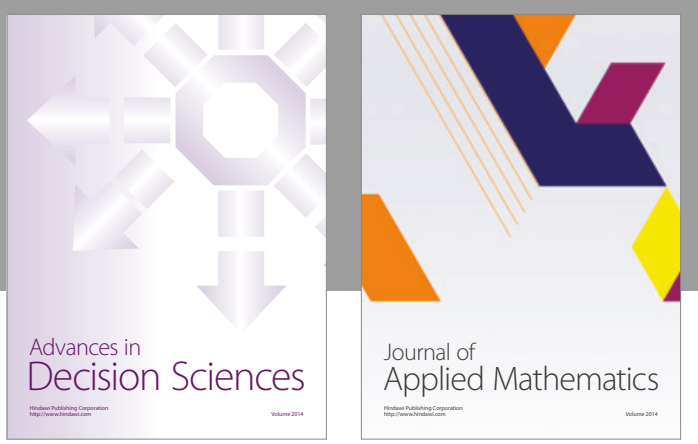

Algebra

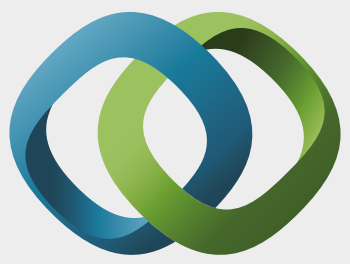

\section{Hindawi}

Submit your manuscripts at

https://www.hindawi.com
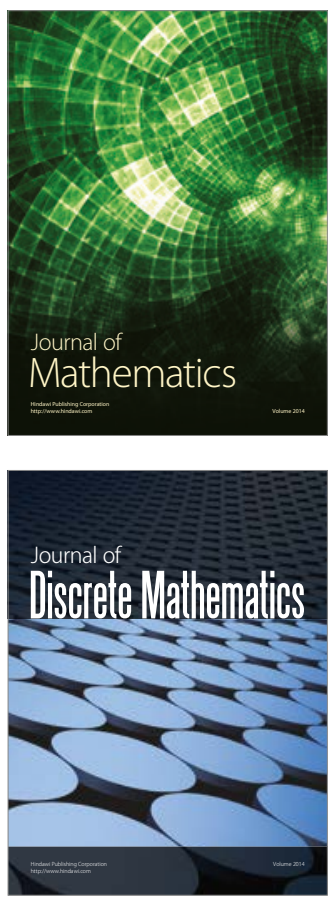

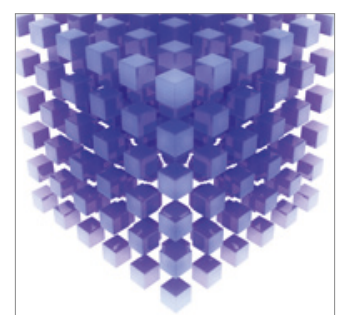

Mathematical Problems in Engineering
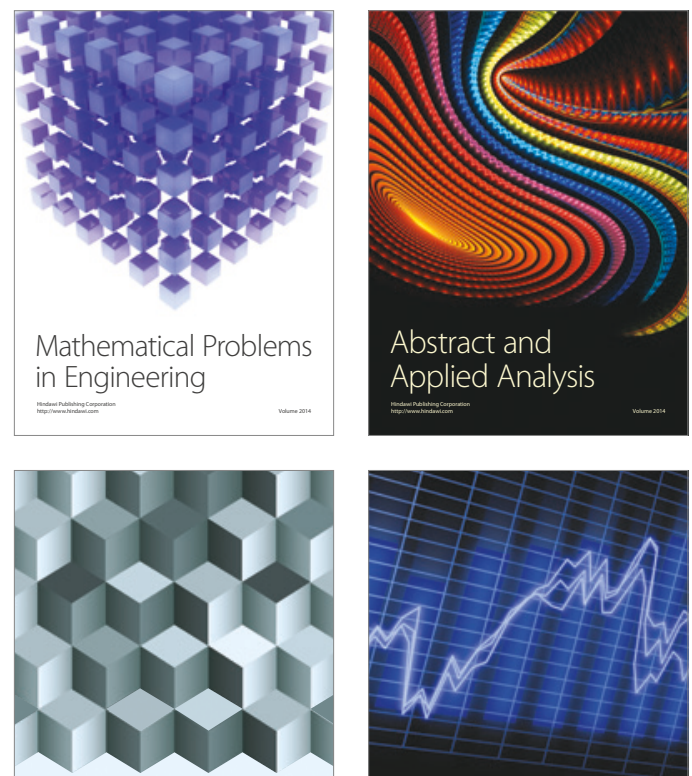

Journal of

Function Spaces

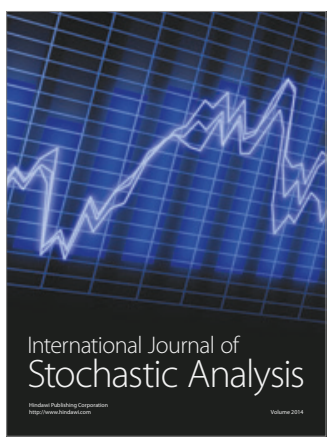

Probability and Statistics
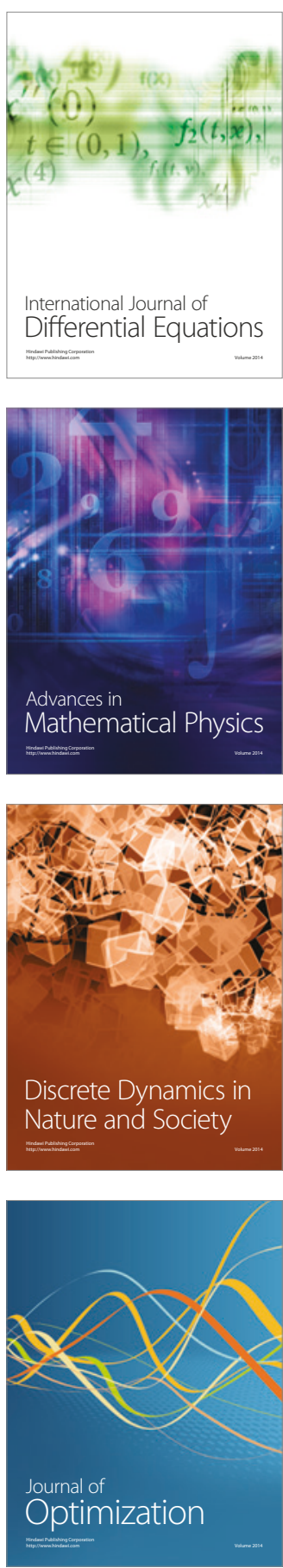